\title{
Arts engagement, mortality and dementia: what can the data say?
}

\author{
Liam Wright
}

June 2020

Does going to a museum make you taller? Unlikely. But taller people may be more likely to attend museums or to engage in receptive art consumption. Height is related to socio-economic background (Bann et al. 2018) and to cognitive ability (Case and Paxson 2008). Both of these could explain any link between art engagement and height, rather than a direct causal relation.

In two recent papers (Fancourt and Steptoe 2019; Fancourt, Steptoe, and Cadar 2020), Fancourt and colleagues find that participants in the English Longitudinal Study of Ageing who engage with the receptive arts have lower rates of mortality and of dementia. In their models, they control for multiple factors which predict mortality, dementia, and arts engagement, such as cognitive ability and financial wealth. But is this enough to account for the heavy social patterning of arts consumption? To explore this, I repeat their main analysis (Fancourt and Steptoe 2019) using height as an outcome variable. ${ }^{1}$ If their regression adjustments do account for social patterning, it seems reasonable to assume we should see no independent association between arts engagement and height. (This is known as a negative control outcome test (Lawlor, Tilling, and Smith 2016).)

The left panel of Figure 1 shows the results of bivariate and multivariate regressions. We see that individuals who engage in the arts are taller on average, even controlling for the array of control variables Fancourt and colleagues use. We also see similar results when we use frequency of eating out at restaurants, internet use, or owning a mobile phone as alternative 'treatment' variables. These variables are likely to be similarly socially patterned.

Does going to a museum increase your life expectancy or reduce your risk of dementia? Perhaps. Fancourt and colleagues give several theoretical arguments for such a link. But I'm unconvinced their data give us any further evidence in support.

Full regression results and replication code are available at https://osf.io/kgqnr/. ${ }^{2}$

\footnotetext{
${ }^{1}$ Model covariates differ slightly across their two papers. I obtain qualitatively similar results using either set of covariates, but report the results from Fancourt and Steptoe (2019) as the set of covariates is larger in this study.

${ }^{2}$ The cognitive variables have not yet been made publicly available. I thank Daisy Fancourt for sharing the data and checking my code for inconsistencies with her work.
} 


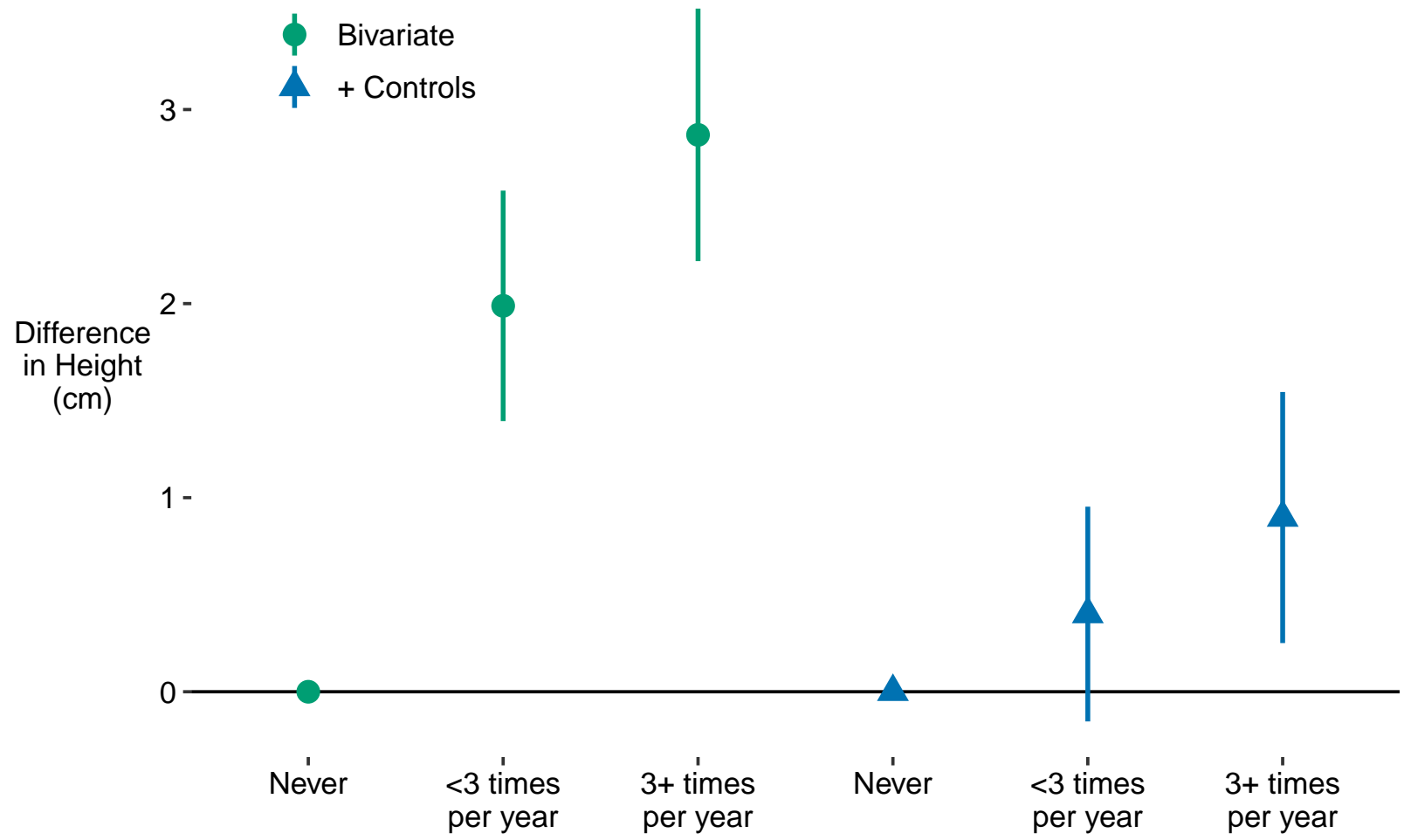

Frequency of Receptive Arts Engagement

Figure 1: Association between height and frequency of receptive arts engagement

\section{References}

Bann, David, William Johnson, Leah Li, Diana Kuh, and Rebecca Hardy. 2018. "Socioeconomic Inequalities in Childhood and Adolescent Body-Mass Index, Weight, and Height from 1953 to 2015: An Analysis of Four Longitudinal, Observational, British Birth Cohort Studies." The Lancet Public Health 3 (4): e194-e203. https://doi.org/10.1016/S2468-2667(18)30045-8.

Case, Anne, and Christina Paxson. 2008. "Stature and Status: Height, Ability, and Labor Market Outcomes." Journal of Political Economy 116 (3): 499-532. https://doi.org/10.1086/589524.

Fancourt, Daisy, and Andrew Steptoe. 2019. "The Art of Life and Death: 14 Year Follow-up Analyses of Associations Between Arts Engagement and Mortality in the English Longitudinal Study of Ageing." BMJ, December, 16377. https://doi.org/10.1136/bmj.16377.

Fancourt, Daisy, Andrew Steptoe, and Dorina Cadar. 2020. "Community Engagement and Dementia Risk: Time-to-Event Analyses from a National Cohort Study." Journal of Epidemiology and Community Health 74 (1): 71-77. https://doi.org/10.1136/jech-2019-213029.

Lawlor, Debbie A., Kate Tilling, and George Davey Smith. 2016. "Triangulation in Aetiological Epidemiology." International Journal of Epidemiology 45 (6): 1866-86. https://doi.org/10.1093/ije/dyw314. 